\title{
Strategic consolidation: The biotechnology business model for the 21st century
}

\section{Is it time to break from the pack in defining your company's future?}

\section{Robert S. Esposito and Marc J. Ostro}

\begin{abstract}
After nearly two decades of observing biotechnology funding cycles, we believe the industry is now undergoing a fundamental change that will necessitate the creation of a radically new business model. While previously biotechnology companies attempted to emulate pharmaceutical companies in laying out their business plans, specialization of both the healthcare and financial markets demands a much more focused approach in the biotechnology sector. What we propose is that the industry needs to undergo a strategic consolidation resulting in the creation of far fewer but vastly stronger, larger, and more "financeable" biotechnology companies. While this concept is often unpopular with industry executives, we see it as the only viable "win-win" solution on the horizon.
\end{abstract}

\section{The emerging cash crisis}

There are a number of indicators suggesting that the biotechnology industry may be entering a cash-liquidity crisis of a magnitude never before seen. This is primarily due to the fact that other high-tech sectors, for obvious reasons, have matured more rapidly than biotechnology and offer investors sustainable growth with less risk. While it is true that biotechnology funding is up $7.5 \%$ over 1997, the fact remains that during this same period, small-cap biotechnology IPOs were priced $17 \%$ below their filing range on average. If one examines how these companies faired post-IPO, their average current trading value is approximately $35 \%$ below the IPO price. This means that in 1998, IPO stocks have lost on average more than $50 \%$ of their initial filing-range value. With this kind of track record, it is clear why small-cap companies do not even appear on the radar screen of most Wall Street analysts, nor fit within the current risk profile of most insti-

Robert S. Esposito is partner and national director, biotechnology and life sciences, and Marc J. Ostro is senior managing director in life science corporate finance at KPMG Peat Marwick LLP, P.O. Box 7348, Princeton, NJ 08543 (resposit@kpmg.com). tutional investors-the primary source of biotechnology stock funding.

Institutional investors have become much more sophisticated in picking biotechnology stocks since the last biotech-funding window opened in 1995-96. This is partially due to the market itself. The three-year bull market beginning in the spring of 1995 and ending in the summer of 1998 ran up equity prices and increased fund flows to the point where money managers have more cash to place than ever before. As a result, they have

\section{Relinquishing the idea that a company with great technology or great science can make it alone requires a dramatic shift in focus for most companies.}

been forced to invest much larger sums. Since most biotechnology companies have too small a market capitalization to justify these kinds of placements, are perceived as too risky, and lack market liquidity, institutional investors have turned to the bigger cap, less volatile stocks as the method of choice to boost bottom-line results.

For the typical fund manager, this means a company needs to have a market cap in excess of $\$ 500$ million to even show up on their investment screen. The tale of the tape tells it all: as of September 30, 1998, 278 of 366 public biotechnology companies traded below $\$ 10$ a share-111 of those trading below $\$ 2$ a share-and on any average day trading volumes per company were less than 80,000 shares.

The strategic consolidation solution Given these sobering statistics, what is a smaller cap biotechnology company to do? The obvious solution is to come up with strategies that will create larger market capitalizations. Our analysis suggests that strate- gic consolidation is the fast-track method to accomplish this goal. We fully realize, given the history of biotechnology, that this will be a difficult decision for most biotechnology executives and their boards of directors. Relinquishing the idea that a company with great technology or great science can make it alone requires a dramatic shift in focus for most companies. It means their emphasis must not only be on discovery, but also on marketing, and ultimately on financial return and liquidity for shareholders in the near- to mid-term, not on a vaguely defined horizon.

\section{A "hypothetical" case in point}

Perhaps the most frustrating part of our strategic advisory consulting with scores of biotechnology and pharmaceutical executives looking for ways to improve their businesses, increase their market capitalization, and solve their critical problems, is that we often see strategic combinations that would enable them to create significant value. These combinations-well within their grasp-are usually discarded out of hand. For example, we were advising three public biotechnology companies involved in cancer-related research. Each of them suffered from languishing stock prices and deeply undervalued core operating fundamentals. If these three public companies were merged, what inherent value could they recognize for investors?

First, they would have six products that had either been approved by the FDA or were nearing approval with a combined sales potential of $\$ 500$ to $\$ 800$ million. Second, they would have $\$ 120$ million in cash. Third, they would have a technology platform that was fully integrated from basic research through FDA approval and one that was oncology specific. Fourth, they would have four state-of-the-art GMP manufacturing facilities, as well as an outstanding oncology-focused sales force capable of marketing the company's oncology product line. With this solid oncology business and critical mass, this company would be in position not only to generate new products internally, 
but also to in-license other oncology products, take them through FDA approval, manufacture, and market them.

But beyond the appeal of the newly formed company's scale for developing and marketing products, it would be of sufficient size to attract a significant infusion of equity capital from institutional investors. Assuming the combined company could earn $\$ 2$ to $\$ 3$ a share within three years, a 30 times profit/earnings multiple could result in a $\$ 60$ to $\$ 90$ share price and a multibillion dollar market valuation. This enhanced market capitalization would also result in increased liquidity for the shareholders. The bottom line would be a profitable company that had passed through biotechnology's "glass ceiling" into consideration as a large-cap company.

\section{No-brainer}

If this sounds like a "no-brainer," consider that this "hypothetical" merger is actually based on fact. Why didn't it materialize? Among other things, fear of near-term dilution and executive egos scuttled this potential merger. As of December 1, 1998, all these companies were individually trading at less than $\$ 8$ per share. Sadly, our experience is that this is not unusual in biotechnology.

A number of factors keep biotechnology companies from pursuing this type of strategic consolidation despite the tremendous upside. Perhaps foremost is that the company's management may be in a state of denial about the true situation they face. Many companies that find themselves in desperate straits are unwilling to acknowledge their constraints and therefore cannot bring themselves to take the necessary steps to improve their fortunes by stepping outside the traditional biotechnology company framework.

For example, many biotechnology companies are influenced by venture capitalists, directors, and executive officers who do not want the stock to suffer dilution as the result of an acquisition. They argue that short-term dilution is worse than the hope of the longer-term appreciation that is likely to result from this type of strategic, wellconceived consolidation. Others accept the argument that they will be in just as bad a situation after the merger as before it with respect to their liquidity and balance sheet. They are persuaded that it is necessary to inject additional capital after a merger to facilitate integration and minimize the company's need for equity capital going forward, and thus do nothing. The truth is that they will more likely have a much easier time improving their balance sheet after consolidation.

Still another biotechnology management philosophy holds true to the "not-invented-here" syndrome that was passed down from their pharmaceutical or academic training. Companies that have some cash often want to spend it on R\&D of their own products, not on the products of a merger partner.

Finally, there is the "one-big-happy-family" factor. A benevolent, but shortsighted biotechnology CEO may be willing to sustain an ill-conceived operating model rather than seek a business relationship that might result in job losses for key executives or employees and could even risk job loss for everyone. The sad moral of the story is that most biotechnology companies have not yet seen the necessity of changing their business strategies even when sorely needed cash and market liquidity is unavailable. They will have to soon, however, for approximately $80 \%$ of biotechnology companies have less than two years of available operating cash, and it is therefore inevitable that many will face dire straits in the foreseeable future.

\section{Work in progress}

Beyond the "what-if" scenario described above, what concrete evidence is there that this strategy will actually work? The good news is that we can point to a number of companies that represent "works-in-progress" in adopting this strategy. One of these is Elan plc, based in Dublin, Ireland.

Several years ago, the management of Elan made a strategic decision to re-engineer their existing business plan. Their core drug delivery business needed increased momentum and their solution was to infuse their product pipeline with an integrated portfolio of synergistic therapeutic products through strategic acquisition and technology collaborations. They realized that to accomplish this they would need cash, and at that time this required more of a US presence.

Beginning with the acquisition of Athena Neurosciences in late 1995, they then acquired Sano, Carnrick Labs, Neurex, and, most recently, NanoSystems. Each of their acquisitions brought a different element to the company-revenue stream, drug delivery systems, products on the market or advanced in the pipeline, and/or a sales force-as well as intimate knowledge of the CNS segment.

Because Elan chose its partners wisely, the company developed a diversified and more predictable revenue profile composed of product sales, royalties and licensing fees, research, and contract revenue. As a result, Wall Street has rewarded Elan with an increased share price after each acquisition, even though each of the companies was acquired at a premium over market. In fact, Elan's share price has quadrupled since 1995. Starting with a pre-acquisition market capitalization of $\$ 1.8$ billion in 1995 , the company was valued at over $\$ 8$ billion in late 1998.

Many Wall Street analysts believe that Elan is positioning itself to ultimately achieving its stated objective of a $\$ 1$ billion revenue base, with $80 \%$ of that revenue derived from sustainable and predictable product sales. By pioneering the "strategic-consolidation" model, Elan has achieved sufficient scale to compete effectively with both global pharmaceutical companies and top-tier biotechnology companies. It has also entered the realm of large-cap companies for institutional investors and has demonstrated sustained growth as well as market liquidity.

\section{Conclusions}

We firmly believe the pace of strategic consolidation will only accelerate as biotechnology executives and directors are forced to recognize the need for synergistic combinations. The drivers in bringing this into the mainstream of biotechnology dealmaking are likely to be a combination of internal and external factors based on the availability or shortage of cash. Although we do not want to be perceived as the harbingers of doom and gloom, it is extremely likely that a major force in developing a trend toward consolidations will be the threat of bankruptcy or delisting of many small-cap biotechnology stocks. Desperate times lead to desperate measures, and experience has shown that companies often seek out partners as a last resort to avoid going out of existence. This scenario does not meet our definition of strategic consolidation. The most successful strategic consolidations will be those that are implemented well before such scenarios come to pass.

It is also likely that venture capitalists and major institutional investors, who cannot cash out of an investment because of the company's low market capitalization and lack of market liquidity, will serve as catalysts for facilitating consolidation between private and public companies. Finally, we expect to see mounting pressure from Wall Street research analysts on biotechnology executives and institutional investors to break away from the pack and adopt the strategic consolidation business model, generating investor interest and creating higher market valuations.

If our predictions are right, deals like the aforementioned hypothetical merger and the successful Elan experience will become the hallmark of biotechnology in 1999 and beyond. With such an upside for individual companies, shareholders, and the biotechnology industry as a whole, perhaps it is time for biotechnology to transfer some of its legendary creativity in R\&D from the benchtop into the board room. /// 